\title{
Functional Images Reflect Aggressiveness of Endometrial Carcinoma: Estrogen Receptor Expression Combined with ${ }^{18}$ F-FDG PET
}

Tetsuya Tsujikawa ${ }^{1}$, Yoshio Yoshida ${ }^{2}$, Takashi Kudo ${ }^{1}$, Yasushi Kiyono ${ }^{1}$, Tetsuji Kurokawa ${ }^{2}$, Masato Kobayashi ${ }^{1}$, Tatsuro Tsuchida ${ }^{3}$, Yasuhisa Fujibayashi ${ }^{1}$, Fumikazu Kotsuji ${ }^{2}$, and Hidehiko Okazawa ${ }^{1}$

${ }^{1}$ Biomedical Imaging Research Center, Faculty of Medical Sciences, University of Fukui, Fukui, Japan; ${ }^{2}$ Department of Gynecology, Faculty of Medical Sciences, University of Fukui, Fukui, Japan; and ${ }^{3}$ Department of Radiology, Faculty of Medical Sciences, University of Fukui, Fukui, Japan

The grade of histologic differentiation is one of the most important prognostic factors in patients with endometrial carcinoma and postoperative staging. The aim of this study was to investigate whether $16 \alpha^{-18} \mathrm{~F}$-fluoro-17 $\beta$-estradiol $\left({ }^{18} \mathrm{~F}-\mathrm{FES}\right)$ and ${ }^{18} \mathrm{~F}-\mathrm{FDG}$ PET reflect clinicopathologic features in patients with endometrial tumors. Methods: A total of 22 patients with endometrial adenocarcinoma and 9 with endometrial hyperplasia (mean age, $56.0 \pm 15.3 \mathrm{y}$ ) underwent ${ }^{18} \mathrm{~F}$-FES PET for estrogen receptor imaging and ${ }^{18} \mathrm{~F}$-FDG $\mathrm{PET}$. Regional values of tracer uptake were evaluated using standardized uptake value (SUV) and the SUV ratio of ${ }^{18} \mathrm{~F}$-FDG to ${ }^{18} \mathrm{~F}$-FES. The accuracy for predicting tumor aggressiveness defined as high-risk carcinoma (International Federation of Gynecology and Obstetrics [FIGO] stage $\geq$ Ic or histologic grade $\geq 2$ ), low-risk carcinoma (FIGO stage $\leq$ $\mathrm{Ib}$ and grade 1), and hyperplasia was compared for each PET parameter using receiver-operating-characteristic (ROC) analysis. The diagnostic accuracy of MRI findings for clinical staging was also compared. Results: Although the SUV for ${ }^{18} \mathrm{~F}-\mathrm{FDG}$ was significantly lower in endometrial hyperplasia than in carcinoma, a significant difference between high-risk and low-risk carcinoma was observed only in SUV for ${ }^{18}$ F-FES. High-risk carcinoma showed a significantly greater ${ }^{18} \mathrm{~F}-\mathrm{FDG}$-to- ${ }^{18} \mathrm{~F}-\mathrm{FES}$ ratio $(3.6 \pm 2.1)$ than did low-risk carcinoma $(1.3 \pm 0.5, P<0.01)$ and hyperplasia $(0.3 \pm 0.1, P<0.005)$. Low-risk carcinoma showed a significantly higher ${ }^{18} \mathrm{~F}-\mathrm{FDG}$-to- ${ }^{18} \mathrm{~F}-\mathrm{FES}$ ratio than hyperplasia $(P<0.0001)$. In ROC analysis, the most accurate diagnostic PET parameter for predicting high-risk and low-risk carcinoma was the ${ }^{18} \mathrm{~F}-\mathrm{FDG}$-to- ${ }^{18} \mathrm{~F}$-FES ratio. The optimal ${ }^{18} \mathrm{~F}-\mathrm{FDG} /{ }^{18} \mathrm{~F}-$ FES cutoff value of 2.0 , determined by ROC analysis, revealed $73 \%$ sensitivity, $100 \%$ specificity, and $86 \%$ accuracy, which was better than the $77 \%$ accuracy for MRI. The ${ }^{18} \mathrm{~F}-\mathrm{FDG}-$ to- ${ }^{18} \mathrm{~F}-\mathrm{FES}$ ratio of 0.5 yielded a correct diagnosis for carcinoma from hyperplasia with $100 \%$ accuracy. Conclusion: Endometrial carcinoma reduces estrogen dependency with accelerated glucose metabolism as it progresses to a higher stage or grade. ${ }^{18} \mathrm{~F}-\mathrm{FES}$ and ${ }^{18} \mathrm{~F}-\mathrm{FDG}$ PET studies provide a new index of the ${ }^{18} \mathrm{~F}-\mathrm{FDG}-$ to- ${ }^{18} \mathrm{~F}-\mathrm{FES}$ ratio, which is considered the most informative index reflecting tumor aggressiveness. This index will

Received Nov. 14, 2008; revision accepted Jan. 16, 2009.

For correspondence or reprints contact: Hidehiko Okazawa,

Biomedical Imaging Research Center, University of Fukui, 23-3

Matsuoka-Shimoaizuki, Eiheiji-cho, Fukui 910-1193, Japan.

E-mail: okazawa@u-fukui.ac.jp

COPYRIGHT ( 2009 by the Society of Nuclear Medicine, Inc. be useful for making noninvasive diagnoses and deciding the appropriate therapeutic strategy for patients with endometrial carcinoma.

Key Words: estrogen receptor; endometrial carcinoma; PET; glucose metabolism; tumor aggressiveness

J Nucl Med 2009; 50:1598-1604

DOI: 10.2967/jnumed.108.060145

E ndometrial carcinoma is a highly prevalent gynecologic malignancy and one of the most common female malignant tumors in Western countries, including the United States, and in Japan (1,2). Early-stage endometrial carcinoma shows a good prognosis, and the 5-y survival rate is reported to be more than $90 \%$ in patients with stage Ia or $\mathrm{Ib}$ determined by the International Federation of Gynecology and Obstetrics (FIGO) classifications (3-5). On the other hand, patients with advanced disease have a significantly worse survival. Up to $20 \%$ of those with endometrial carcinoma relapse and eventually die of their disease. Previous studies suggested that the most important prognostic factors in endometrial carcinoma were the surgical FIGO stage, myometrial invasion, histologic type, and differentiation grade (6-10). A noninvasive diagnostic method to evaluate tumor aggressiveness and pathologic features would be useful for deciding the therapeutic strategy and predicting prognosis in patients with endometrial carcinoma.

We previously reported that estrogen receptor (ER) expression coupled with glucose metabolism using $16 \alpha-{ }^{18} \mathrm{~F}$-fluoro-17 $\beta$-estradiol (FES) and ${ }^{18} \mathrm{~F}$-FDG PET is useful for the differential diagnosis of benign and malignant uterine tumors (11). ER expression and glucose metabolism of uterine tumors showed opposite tendencies (i.e., high glucose metabolism and low ER expression in malignant tumors and low glucose metabolism and high ER expression in benign tumors). The purpose of the present study was to investigate whether regional accumulation of 
${ }^{18} \mathrm{~F}$-FES and ${ }^{18} \mathrm{~F}$-FDG and the uptake ratio of ${ }^{18} \mathrm{~F}$-FDG to ${ }^{18} \mathrm{~F}$-FES correlate with the aggressiveness of endometrial tumors in terms of stage and pathologic findings.

\section{MATERIALS AND METHODS}

\section{Patients}

Thirty-one patients (mean age, $56.0 \pm 15.3$ y) with endometrial thickening or suspected malignant tumors at cytologic analysis, ultrasonography, or MRI participated in this study. None of the patients received any biopsy or treatment before PET and MRI studies. Definitive diagnosis was determined by postoperative histopathologic analysis $(n=25)$ or whole-endometrium curettage $(n=6)$. Final diagnoses were endometrial adenocarcinoma $(n=22)$ and hyperplasia $(n=9)$ (Table 1). All 6 cases determined by whole-endometrium curettage were endometrial hyperplasia. In surgically staged patients, the final stage and grade were decided by findings at hysterectomy. The staging, histology, and grading criteria were based on the 1988 FIGO staging classification (3). The results for 9 patients with endometrial carcinoma and 4 patients with hyperplasia were previously reported in our recent study (11). This study was approved by the institutional review board of the University of Fukui Hospital. Written informed consent was obtained from all patients studied.

\section{PET Procedures}

All patients underwent preoperative PET scans with ${ }^{18} \mathrm{~F}-\mathrm{FES}$ and ${ }^{18} \mathrm{~F}-\mathrm{FDG}$ to compare differences in tracer accumulation. Two scans were obtained on 2 separate days within $1 \mathrm{wk}$ in random sequence. We used a whole-body tomograph (Advance; GE Healthcare) that permits the simultaneous acquisition of 35 image

\section{TABLE 1. Patient Characteristics}

\begin{tabular}{|c|c|}
\hline Characteristic & Value \\
\hline Total patients $(n)$ & 31 \\
\hline Mean age $(y)$ & $56 \pm 15$ \\
\hline Age range $(y)$ & $30-84$ \\
\hline \multicolumn{2}{|l|}{ Menopausal status $(n)$} \\
\hline Premenopausal & 13 \\
\hline Postmenopausal & 18 \\
\hline \multicolumn{2}{|l|}{ Histopathologic type $(n)$} \\
\hline Endometrial adenocarcinoma & 22 \\
\hline Endometrial hyperplasia & 9 \\
\hline \multicolumn{2}{|l|}{ Stage of carcinoma $(n)$} \\
\hline la or lb & 14 \\
\hline Ic & 3 \\
\hline$\|$ & 2 \\
\hline III & 3 \\
\hline \multicolumn{2}{|l|}{ Differentiation grade $(n)$} \\
\hline G1 & 12 \\
\hline G2 & 9 \\
\hline G3 & 1 \\
\hline \multicolumn{2}{|l|}{ Tumor size $(n)$} \\
\hline$<1 \mathrm{~cm}$ & 14 \\
\hline $1-2 \mathrm{~cm}$ & 8 \\
\hline $2 \mathrm{~cm}<$ & 9 \\
\hline High-risk carcinoma $(n)$ & 11 \\
\hline Low-risk carcinoma (n) & 11 \\
\hline \multicolumn{2}{|c|}{$\begin{array}{l}\text { Carcinoma of stage lb or lower with grade } \mathrm{G} 2 \text { or } \mathrm{G} 3 \text { was } \\
\text { included in high-risk group. }\end{array}$} \\
\hline
\end{tabular}

slices in a 2-dimensional acquisition mode, with interslice spacing of $4.25 \mathrm{~mm}$. Performance tests showed the intrinsic resolution of the scanner to be $4.0-5.3 \mathrm{~mm}$ in the axial direction and 4.6-5.7 $\mathrm{mm}$ in the transaxial direction.

${ }^{18} \mathrm{~F}$-FES was synthesized using a method reported elsewhere $(12,13)$. The specific activity was $100-200 \mathrm{GBq} / \mu \mathrm{mol}$, and radiochemical purity was greater than $99 \%$. For each ${ }^{18} \mathrm{~F}$-FES and ${ }^{18}$ F-FDG PET study, approximately $185 \mathrm{MBq}$ of tracer were administered via the antecubital vein. Before the tracer administration of each study, patients fasted at least $4 \mathrm{~h}$ to avoid elevation of blood sugar levels in ${ }^{18} \mathrm{~F}-\mathrm{FDG}$ PET and to reduce tracer excretion to the intestines in ${ }^{18} \mathrm{~F}$-FES PET. Fifty minutes after the tracer injection, the patient was positioned supine in the PET scanner, and a 16-min emission scan was started, with 3-min scans at the pelvic region ( 2 bed positions) and 2-min scans in each remaining region ( 5 bed positions) to completely cover the head to inguinal regions. Postinjection transmission scans of $2 \mathrm{~min}$ at the pelvis and $1 \mathrm{~min}$ in other areas were obtained after the emission scans using a ${ }^{68} \mathrm{Ge} /{ }^{68} \mathrm{Ga}$ rod source for attenuation correction. The PET data were reconstructed by the iterative method, with selection of 14 subsets and 2 iterations. The reconstructed images were then converted to a semiquantitative image corrected by the injection dose and the patient's body weight (standardized uptake value $[\mathrm{SUV}])$ for data analysis.

\section{MRI Scans and SUV Measurements}

All patients underwent MRI during the time between the 2 PET examinations, or within $1 \mathrm{wk}$ from them, for diagnosis and to obtain anatomic information about the pelvic organs. T1- and T2weighted images in the axial, sagittal, and coronal planes were acquired with a 1.5-T superconducting MRI system (Signa; GE Healthcare). The repetition and echo times for T1- and T2weighted images were 533 and $8 \mathrm{~ms}$ and 4,700 and $90 \mathrm{~ms}$, respectively. Contrast-enhanced MRI was performed with or without fat saturation in the axial and sagittal planes after the injection of gadolinium diethylenetriamine pentaacetic acid $(0.1$ $\mathrm{mmol} / \mathrm{kg}$ ). Staging of the tumors based on MRI findings was performed by board-certified radiologists as follows: intact junctional zone on T2-weighted MR images and superficial myometrial invasion (no more than half) on T2- and contrast T1-weighted images were regarded as early stages and deep myometrial invasion (more than half), cervical involvement, and pelvic lymphadenopathy as advanced stages.

Circular regions of interest (ROIs) with a fixed size of $8 \mathrm{~mm}$ in diameter were drawn on the lesions to obtain the local SUV. Individual MR images were referenced for placement of ROIs in the appropriate region after PET and MR images were coregistered (Body Guide; Advance Biologic Co.). ROIs were placed on the resliced MRI sections after coregistration of 3 images in each patient and the same ROIs were applied to the ${ }^{18} \mathrm{~F}-\mathrm{FES}$ and ${ }^{18} \mathrm{~F}$ FDG PET images. Sagittal or coronal planes (2 or 3) of 6-mm thickness were used to obtain SUV at the center of the lesion. A single section at the center of the lesion was used when the lesion was small and substantial partial-volume effects on the mean SUV were expected. SUVs for each patient were averaged in ${ }^{18} \mathrm{~F}-\mathrm{FDG}$ and ${ }^{18} \mathrm{~F}$-FES PET images. The mean SUV ratio of ${ }^{18} \mathrm{~F}$-FDG to ${ }^{18} \mathrm{~F}-$ FES for each lesion was also calculated.

\section{Data Analysis}

All patients were divided into 3 groups. The first group was high-risk endometrial carcinoma with FIGO stage higher than Ib 
or histologic grade higher than grade 1. The second group was low-risk carcinoma with FIGO stage Ib or Ia and histologic grade 1. The third group was endometrial hyperplasia. SUVs for ${ }^{18} \mathrm{~F}-$ FDG and ${ }^{18} \mathrm{~F}-\mathrm{FES}$ and the ${ }^{18} \mathrm{~F}-\mathrm{FDG}-$ to- ${ }^{18} \mathrm{~F}-\mathrm{FES}$ ratio were compared among the 3 groups by 1-way ANOVA with a post hoc Games-Howell test, which has robustness for analysis even in unequal variance. Differences in tracer accumulation were also compared between the 2 tracers using a paired $t$ test. Statistical analysis was performed using a software package (SPSS for Microsoft Windows, version 11.5.1 J; SPSS Inc.).

Receiver-operating-characteristic (ROC) analysis was performed to determine diagnostic accuracy and the optimal cutoff value to differentiate high- versus low-risk groups and low-risk versus hyperplasia groups using MedCalc (version 7.6.0.0; MedCalc Software). The area under the ROC curve (AUC) provided a measure for the accuracy of a diagnostic test by PET parameters. The diagnostic accuracy of MRI, compared with postoperative definitive diagnosis, was evaluated by an ability to distinguish carcinoma in advanced stages (FIGO stage $\geq$ Ic) from early stages (FIGO stage $\leq \mathrm{Ib}$ ) irrespective of histologic grade. The accuracy of MRI findings and PET parameters was also compared using the McNemar test. A probability value of less than 0.05 was considered to indicate a significant difference.

\section{RESULTS}

\section{SUVs and Ratio}

Table 1 summarizes patient characteristics including tumor stage and lesion size. Thirteen patients were premenopausal and 18 were postmenopausal. The mean SUVs and ${ }^{18} \mathrm{~F}-\mathrm{FDG}-\mathrm{to}-{ }^{18} \mathrm{~F}-\mathrm{FES}$ ratios for each group are given in Table 2. Patients with high-risk endometrial carcinoma showed a significantly higher accumulation of ${ }^{18} \mathrm{~F}-\mathrm{FDG}$ than ${ }^{18} \mathrm{~F}$-FES $(P<0.0001$, paired $t$ test $)$, whereas patients with low-risk carcinoma did not show a significant difference between ${ }^{18}$ F-FDG and ${ }^{18}$ F-FES uptake. In contrast, endometrial hyperplasia showed a significantly higher uptake for ${ }^{18} \mathrm{~F}$-FES than ${ }^{18} \mathrm{~F}$-FDG $(P<0.005)$ in the primary tumors. Figure 1 shows the tendencies toward an increase in ${ }^{18} \mathrm{~F}$-FDG uptake and a decrease in ${ }^{18} \mathrm{~F}$-FES as disease progressed to a higher stage or histologic grade. ${ }^{18} \mathrm{~F}-\mathrm{FDG}$ accumulation was not significantly different between highrisk and low-risk endometrial carcinoma, although hyperplasia showed significantly lower ${ }^{18}$ F-FDG accumulation than did high-risk $(P<0.0001)$ and low-risk $(P<0.005)$ carcinoma. ${ }^{18} \mathrm{~F}$-FES PET showed a significant difference between these 2 groups of carcinoma $(P<0.05)$. In Figure
2 , high-risk carcinoma showed a significantly greater ${ }^{18} \mathrm{~F}-$ FDG-to- ${ }^{18}$ F-FES ratio than did low-risk carcinoma $(P<$ $0.01)$ and endometrial hyperplasia $(P<0.005)$. Low-risk carcinoma also showed a significantly higher ${ }^{18} \mathrm{~F}-\mathrm{FDG}-$ to- ${ }^{18}$ F-FES ratio than hyperplasia $(P<0.0001)$.

\section{ROC Analysis and Comparison with MRI}

AUCs obtained from ROC analysis for distinction of high- and low-risk carcinoma were $0.90,0.81$, and 0.72 for the ${ }^{18}$ F-FDG-to- ${ }^{18}$ F-FES ratio, ${ }^{18}$ F-FES SUV, and ${ }^{18}$ F-FDG SUV, respectively, indicating that the ${ }^{18}$ F-FDG-to- ${ }^{18}$ F-FES ratio is the most informative index for differentiating aggressiveness of carcinoma although no significant difference was observed in AUCs by the $z$ test. Table 3 shows the diagnostic accuracy for the 3 PET parameters and MRI findings for distinction of high-risk from low-risk carcinoma. ROC analysis determined the optimal cutoff value for each PET parameter to distinguish high- and low-risk carcinoma. The optimal ${ }^{18} \mathrm{~F}-\mathrm{FDG}-\mathrm{to}-{ }^{18} \mathrm{~F}-\mathrm{FES}$ cutoff ratio of 2.0 provided $73 \%$ sensitivity and $100 \%$ specificity, which yielded the greatest accuracy of $86 \%$ among all PET parameters and MRI. Because all lesions of endometrial hyperplasia showed a low ${ }^{18} \mathrm{~F}-\mathrm{FDG}-\mathrm{to}-{ }^{18} \mathrm{~F}-\mathrm{FES}$ ratio of less than 0.5 , a cutoff ratio of 0.5 could distinguish all cases of low-risk carcinoma from hyperplasia correctly, yielding no false-positive findings and $100 \%$ accuracy. A cutoff ${ }^{18} \mathrm{~F}$ FDG SUV of 2.0 also differentiated malignant tumors from benign lesions (Fig. 1). The accuracies of PET parameters and MRI findings were statistically compared, and a significant difference was observed between the ${ }^{18} \mathrm{~F}-\mathrm{FDG}-$ to- ${ }^{18}$ F-FES ratio and ${ }^{18}$ F-FDG SUV $(P<0.005$, McNemar test).

\section{Representative Cases}

Representative images of each group are given in Figures 3-5. Figure 3 shows high-risk endometrial carcinoma (FIGO stage Ic, histologic grade 2). MRI findings suggested no myometrial invasion (stage Ia), and PET images showed high ${ }^{18} \mathrm{~F}$-FDG and moderate ${ }^{18} \mathrm{~F}$-FES accumulation in the primary tumor, with an ${ }^{18} \mathrm{~F}$-FDG-to- ${ }^{18} \mathrm{~F}-\mathrm{FES}$ ratio of 2.5 , indicating high-risk carcinoma. Figure 4 is a case of lowrisk endometrial carcinoma (FIGO stage $\mathrm{Ib}$, histologic grade 1) showing high ${ }^{18} \mathrm{~F}-\mathrm{FDG}$ and ${ }^{18} \mathrm{~F}-\mathrm{FES}$ uptake with an ${ }^{18} \mathrm{~F}-\mathrm{FDG}$-to- ${ }^{18} \mathrm{~F}-\mathrm{FES}$ ratio of 1.3 . MRI also indicated early-stage endometrial carcinoma with superficial myo-

\begin{tabular}{|c|c|c|c|c|}
\hline Class & Patients & ${ }^{18} \mathrm{~F}-\mathrm{FDG}$ SUV & ${ }^{18}$ F-FES SUV & ${ }^{18} \mathrm{~F}-\mathrm{FDG}$-to- ${ }^{18} \mathrm{~F}-\mathrm{FES}$ ratio \\
\hline High-risk carcinoma (stage $\geq$ Ic or grade $\geq 2$ ) & 11 & $9.9 \pm 2.6^{*}(5.4-14.8)$ & $3.4 \pm 1.6(1.3-6.3)$ & $3.6 \pm 2.1(1.3-7.4)$ \\
\hline Low-risk carcinoma (stage $\leq \mathrm{lb}$ and grade 1 ) & 11 & $7.1 \pm 3.7(2.4-12.5)$ & $5.3 \pm 1.8(2.1-8.1)$ & $1.3 \pm 0.5(0.5-1.8)$ \\
\hline Endometrial hyperplasia & 9 & $1.5 \pm 0.3(1.1-1.9)$ & $5.6 \pm 2.4^{\dagger}(2.7-11.0)$ & $0.3 \pm 0.1(0.2-0.4)$ \\
\hline
\end{tabular}




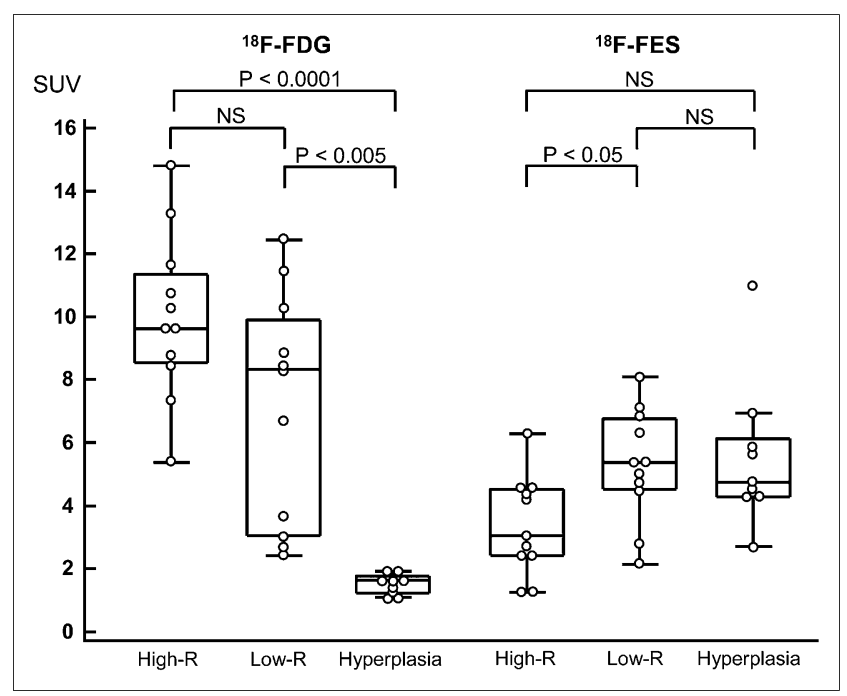

FIGURE 1. Box-and-whisker plots of uptake of each tracer among 3 groups. Horizontal bars inside boxes indicate median values. Error bars indicate farthest points that are not outliers. Significant differences in ${ }^{18} \mathrm{~F}-\mathrm{FDG}$ accumulation were observed between hyperplasia and high-risk $(P<$ $0.0001)$ or low-risk $(P<0.005)$ endometrial carcinoma. ${ }^{18} \mathrm{~F}-$ FDG accumulation was not significantly different between high-risk and low-risk carcinoma, although ${ }^{18} \mathrm{~F}$-FES PET showed significant difference between these 2 groups $(P<$ 0.05). High-R = high-risk carcinoma; low- $\mathrm{R}=$ low-risk carcinoma; NS = not significant.

metrial invasion (Ib). Endometrial hyperplasia had a high level of ${ }^{18} \mathrm{~F}$-FES accumulation corresponding to the thickening of endometrium on MRI (Fig. 5). The ${ }^{18}$ F-FDGto- ${ }^{18} \mathrm{~F}-\mathrm{FES}$ ratio of this patient was 0.2 .

\section{DISCUSSION}

Our recent PET study using ${ }^{18} \mathrm{~F}-\mathrm{FES}$ and ${ }^{18} \mathrm{~F}-\mathrm{FDG}$ revealed that uterine tumors had opposite tendencies in terms of ${ }^{18} \mathrm{~F}$-FES and ${ }^{18} \mathrm{~F}$-FDG accumulation, which represents ER expression and glucose metabolism, between benign and malignant lesions (11). Thus, PET studies with the 2 tracers were useful to provide pathophysiologic information for the differential diagnosis of uterine tumors. In the present study with a larger sample size of endometrial tumors, 2 PET images could distinguish endometrial carcinoma from benign lesions with PET parameters of ${ }^{18} \mathrm{~F}-$ FDG SUV and ${ }^{18} \mathrm{~F}-\mathrm{FDG}-$-to- ${ }^{18} \mathrm{~F}-\mathrm{FES}$ ratio. Furthermore, the regional ${ }^{18} \mathrm{~F}-\mathrm{FDG}-\mathrm{to}-{ }^{18} \mathrm{~F}-\mathrm{FES}$ ratio and the ${ }^{18} \mathrm{~F}$-FES SUV could distinguish high-risk carcinoma (FIGO stage $\geq$ Ic or histologic grade $\geq 2$ ) from low-risk carcinoma (FIGO stage $\leq \mathrm{Ib}$ and histologic grade 1 ). This index provided the information that endometrial carcinoma with an advanced stage or a higher grade reduces estrogen dependency with an increase in glucose metabolism. In contrast, endometrial hyperplasia showed a significantly low ${ }^{18} \mathrm{~F}-\mathrm{FDG}-\mathrm{to}-{ }^{18} \mathrm{~F}-$ FES ratio of less than 0.5, indicating its preserved ER expression without an increase in glucose consumption.

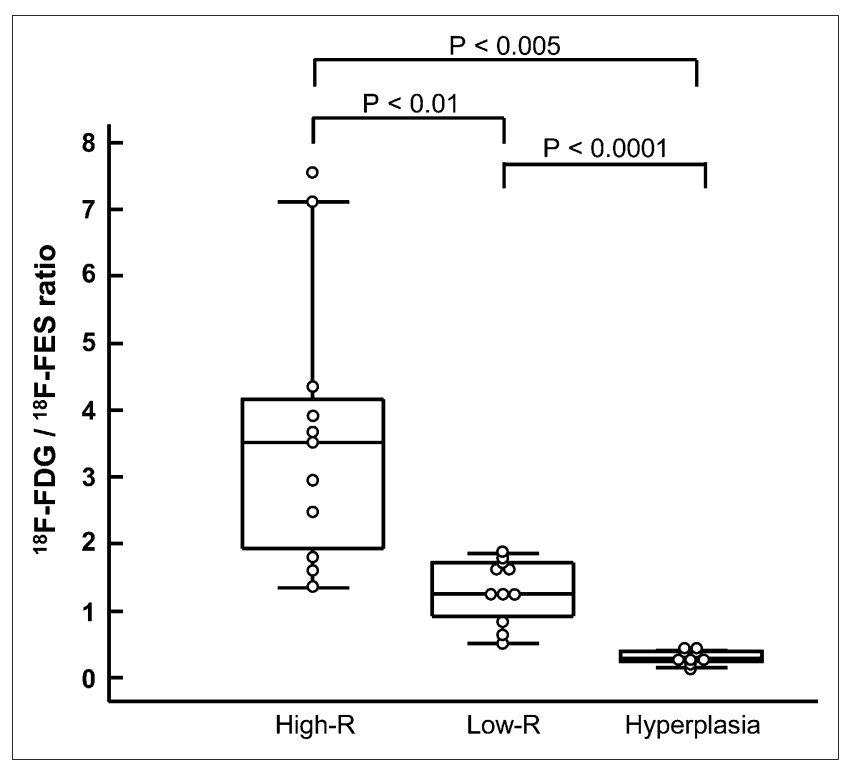

FIGURE 2. Box-and-whisker plots of ${ }^{18} \mathrm{~F}$-FDG-to- ${ }^{18} \mathrm{~F}-\mathrm{FES}$ SUV ratio among 3 groups. Significant differences were observed between high-risk and low-risk carcinoma $(P<$ $0.01)$, between high-risk carcinoma and hyperplasia $(P<$ $0.005)$, and between low-risk carcinoma and hyperplasia $(P<0.0001)$. High- $\mathrm{R}=$ high-risk carcinoma; low- $\mathrm{R}=$ lowrisk carcinoma.

Low-risk carcinoma with moderate-to-intense ${ }^{18} \mathrm{~F}$-FDG and ${ }^{18} \mathrm{~F}$-FES accumulation is considered between high-risk carcinoma and hyperplasia in terms of aggressiveness.

Several reports indicated that ${ }^{18} \mathrm{~F}$-FDG PET is useful for managing pre- and postoperative patients with endometrial carcinoma mainly by detecting lymph node metastasis (14-17). The classification of tumor characteristics determined by ${ }^{18} \mathrm{~F}$-FDG uptake and the ${ }^{18} \mathrm{~F}-\mathrm{FDG}-$ to- ${ }^{18} \mathrm{~F}$-FES ratio could play an important role in the differential diagnosis of endometrial lesions and in deciding the therapeutic strategy. The cutoff ${ }^{18} \mathrm{~F}-\mathrm{FDG}-\mathrm{to}-{ }^{18} \mathrm{~F}-\mathrm{FES}$ ratio of 0.5 and the ${ }^{18} \mathrm{~F}$-FDG SUV of 2.0 could differentiate lowrisk carcinoma from hyperplasia, and all malignancies were correctly distinguished from benign lesions, with no falsepositive findings and $100 \%$ accuracy. Some characteristic MRI findings of benign endometrial lesions such as endometrial hyperplasia and polyps were reported previously $(18,19)$. Those specific findings are occasionally detected in the case of relatively large tumor volume, whereas it is difficult to differentiate small-sized endometrial hyperplasia from stage Ia carcinoma. PET, which characterizes tumor biofunction, would be more reliable than MRI findings for the preoperative diagnosis. Uterine tumors with estrogendependent function such as endometrial carcinoma may lose their estrogen-dependent function, reduce ER expression, and increase glucose metabolism because of aberrant glycolysis with dedifferentiation. This functional transformation could have shown opposite tendencies of high glucose metabolism and low ${ }^{18} \mathrm{~F}$-FES accumulation in malignant 


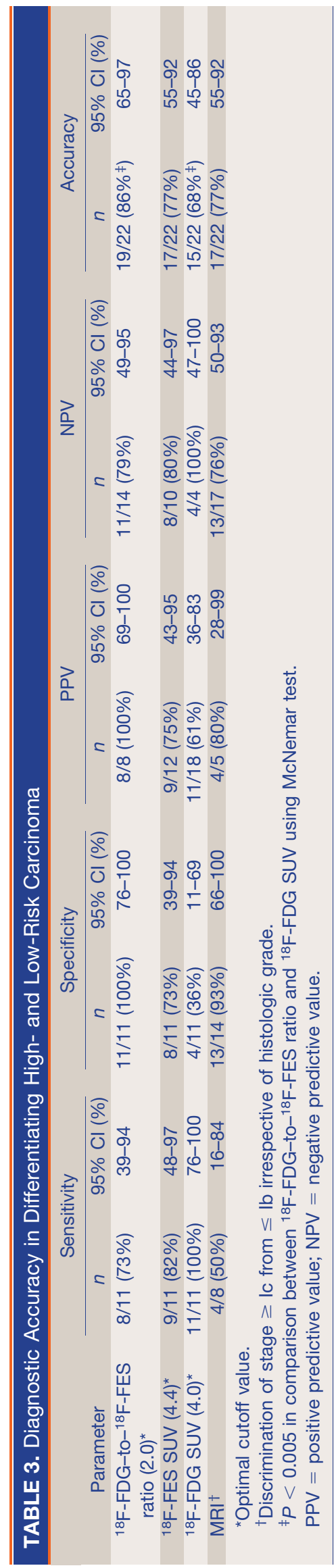

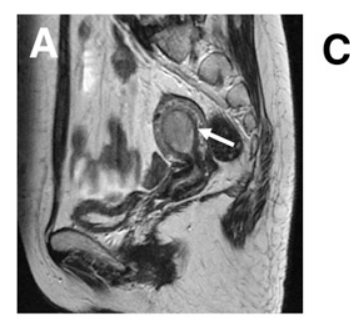
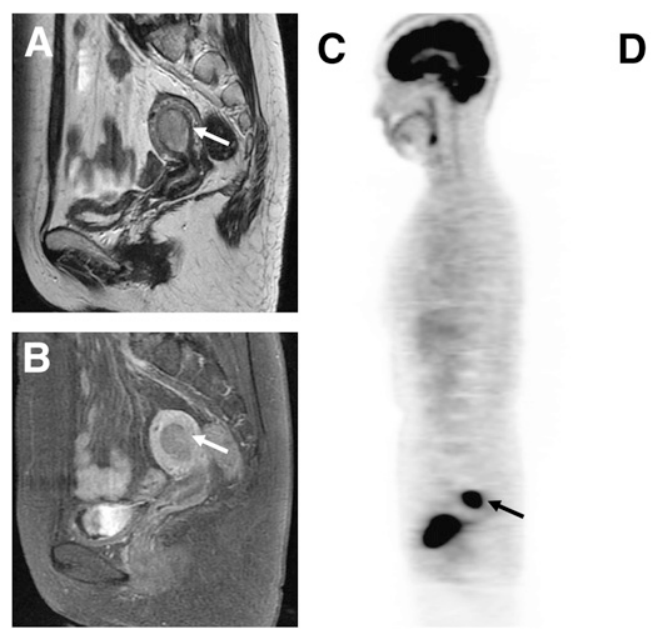

FIGURE 3. T2-weighted (A), contrast-enhanced T1-weighted MR (B), ${ }^{18} \mathrm{~F}-\mathrm{FDG}(\mathrm{C})$, and ${ }^{18} \mathrm{~F}$-FES PET (D) images of 60-y-old woman with endometrial carcinoma (arrows). PET images showed intense ${ }^{18} \mathrm{~F}-\mathrm{FDG}$ uptake (SUV, 11.6) and moderate ${ }^{18} \mathrm{~F}-\mathrm{FES}$ uptake (SUV, 4.7) in tumor. Preoperative staging by MRI suggested no myometrial invasion, whereas PET findings with an ${ }^{18} \mathrm{~F}-\mathrm{FDG}$-to- ${ }^{18} \mathrm{~F}-$ FES ratio of 2.5 indicated high-risk carcinoma. Postoperative histopathologic result was high-risk carcinoma with FIGO stage Ic and histologic grade 2 .

tumors, especially in high-risk carcinoma. This noninvasive method could avoid unnecessary operations or invasive whole-endometrium curettage, which is important for preserving women's reproductive potential.

Functional PET is considered a promising method for deciding on personalized treatment. Although it would be difficult to determine the histologic grade of endometrial lesions by pelvic MRI, PET scans with ${ }^{18} \mathrm{~F}$-FES and ${ }^{18} \mathrm{~F}-$ FDG can reflect tumor aggressiveness (invasiveness and grade) using the index of ${ }^{18} \mathrm{~F}$-FDG-to- ${ }^{18}$ F-FES ratio. As shown in the present study, the diagnostic accuracy of the ${ }^{18} \mathrm{~F}-\mathrm{FDG}-\mathrm{to}-{ }^{18} \mathrm{~F}-\mathrm{FES}$ ratio was better than that of MRI in distinguishing high-risk from low-risk carcinoma. Surgical pathologic staging is now the standard of care for endometrial carcinoma (3). However, the role of comprehensive surgical staging, especially pelvic and paraaortic lymphadenectomy for all patients, remains controversial. Several reports asserted that patients with low-risk endometrial carcinoma can be treated with hysterectomy only $(20,21)$. Avoiding lymphadenectomy decreases complications after surgery. Patients with low-risk endometrial carcinoma determined by an ${ }^{18}$ F-FDG-to- ${ }^{18}$ F-FES ratio of less than 2.0 may be able to avoid pelvic or paraaortic lymphadenectomy, although the cutoff values for PET parameters should be validated prospectively using an independent patient group in further study because the cutoffs were optimized from this particular dataset. To decrease unnecessary lymphadenectomy and establish a noninvasive evaluation method for risk management in patients with endometrial 

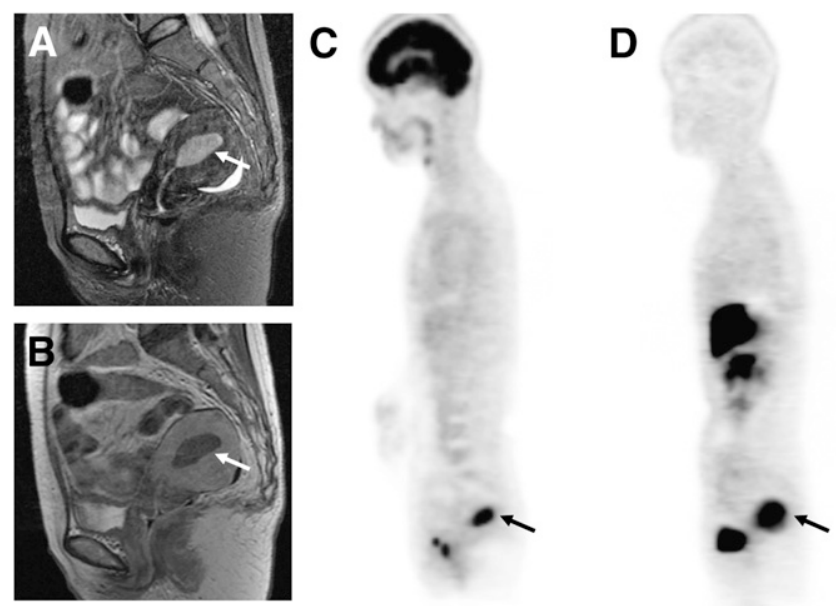

FIGURE 4. Sagittal T2-weighted (A), contrast-enhanced T1-weighted MR (B), ${ }^{18} \mathrm{~F}-\mathrm{FDG}(\mathrm{C})$, and ${ }^{18} \mathrm{~F}-\mathrm{FES}$ PET (D) images of 50-y-old woman with low-risk endometrial carcinoma (FIGO stage Ib and histologic grade 1, arrows). PET images showed intense accumulation for both tracers in endometrial lesion. Region of ${ }^{18} \mathrm{~F}-\mathrm{FES}$ uptake (SUV, 8.1) appeared larger than that of ${ }^{18} \mathrm{~F}-\mathrm{FDG}$ (SUV, 10.2) because of ${ }^{18} \mathrm{~F}$-FES avidity in myometrial inner layer. ${ }^{18} \mathrm{~F}-\mathrm{FDG}$-to- ${ }^{18} \mathrm{~F}-$ FES ratio was 1.3.

carcinoma, further PET studies with a larger patient sample and a long-term follow-up would be needed.

The present study included 2 patients with paraaortic and pelvic lymph node metastases (stage IIIc) among 11 patients high-risk carcinomas. All metastatic lymph nodes were detected correctly by ${ }^{18} \mathrm{~F}-\mathrm{FDG}$ PET, whereas the lymph nodes could not be identified with MRI in one of the patients. Although MRI findings are superior to ${ }^{18} \mathrm{~F}-\mathrm{FDG}$ PET parameters in terms of the regional discrimination of
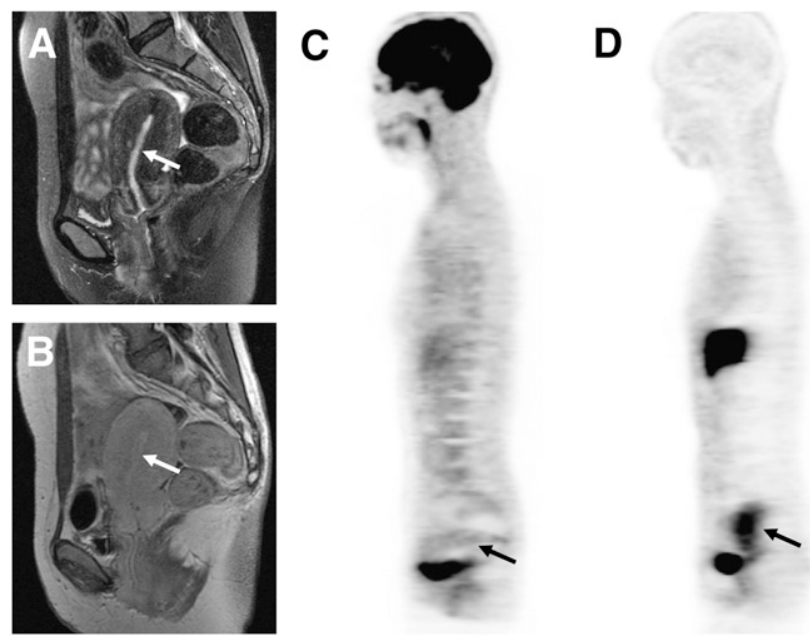

FIGURE 5. A 39-y-old woman who had endometrial hyperplasia with relatively low intensity on sagittal T2-weighted (A) and contrast-enhanced T1-weighted (B) MR images (arrows). PET images showed low ${ }^{18} \mathrm{~F}-\mathrm{FDG}(\mathrm{SUV}, 1.4)(\mathrm{C})$ and high ${ }^{18} \mathrm{~F}-$ FES (SUV, 5.9) (D) accumulation in endometrial lesion of uterus. ${ }^{18} \mathrm{~F}-\mathrm{FDG}$-to- ${ }^{18} \mathrm{~F}-\mathrm{FES}$ ratio was 0.2 . carcinoma in stage Ia or Ib from stage Ic (or higher), ${ }^{18} \mathrm{~F}$-FDG PET is considered to show a higher detection rate than MRI for distant metastasis. In addition, histopathologic results of the cases with lymph node metastases were grades 2 and 3, in which the primary sites showed far higher ${ }^{18}$ F-FDG-to- ${ }^{18}$ F-FES ratios $(4.3$ and 7.1 , respectively) than the cutoff value. These results indicate that PET studies with ${ }^{18} \mathrm{~F}$-FDG and ${ }^{18} \mathrm{~F}$-FES will reflect tumor aggressiveness, which is useful information for the treatment of patients with endometrial lesions.

Although simple stage differentiation with PET parameters was also evaluated by ROC analysis, this method could not differentiate early stages from advanced stages because stage Ia or Ib carcinoma with grades 2 or 3 showed a tracer uptake tendency similar to that of the high-risk group. Thus, we did not use this simple classification in the present study. The differentiation of high- and low-risk tumors as determined here would be more appropriate for the evaluation of tumor aggressiveness.

\section{CONCLUSION}

Endometrial carcinoma reduces estrogen dependency with increased glucose metabolism as it progresses to a higher stage or grade. The ${ }^{18} \mathrm{~F}-\mathrm{FDG}-\mathrm{to}-{ }^{18} \mathrm{~F}-\mathrm{FES}$ ratio calculated from ${ }^{18} \mathrm{~F}$-FES and ${ }^{18} \mathrm{~F}-\mathrm{FDG}$ PET is the most informative index reflecting tumor aggressiveness. This index will be useful for noninvasive diagnosis and for deciding on the appropriate therapeutic strategy for patients with endometrial carcinoma.

\section{ACKNOWLEDGMENTS}

We thank the doctors of the Departments of Radiology and Gynecology, Faculty of Medical Sciences, and the staff of the Biological Imaging Research Center, University of Fukui, for clinical and technical support. This study was partly funded by the Research and Development Project Aimed at Economic Revitalization (Leading Project) from MEXT Japan and a Grant-in-Aid for Scientific Research (20790887) and the 21st Century COE Program (Medical Science) from the Japan Society for the Promotion of Science.

\section{REFERENCES}

1. Jemal A, Siegel R, Ward E, et al. Cancer statistics, 2007. CA Cancer J Clin. 2007;57:43-66.

2. Amant F, Moerman P, Neven P, Timmerman D, Van Limbergen E, Vergote I. Endometrial cancer. Lancet. 2005;366:491-505.

3. Creasman WT. Announcement: FIGO stages-1988 revision. Gynecol Oncol. 1989;35:125-127.

4. Podczaski E, Kaminski P, Gurski K, et al. Detection and patterns of treatment failure in 300 consecutive cases of "early" endometrial cancer after primary surgery. Gynecol Oncol. 1992;47:323-327.

5. Carey MS, O'Connell GJ, Johanson CR, et al. Good outcome associated with a standardized treatment protocol using selective postoperative radiation in patients with clinical stage I adenocarcinoma of the endometrium. Gynecol Oncol. 1995;57:138-144.

6. Boronow RC, Morrow CP, Creasman WT, et al. Surgical staging in endometrial cancer: clinical-pathologic findings of a prospective study. Obstet Gynecol. 1984;63:825-832. 
7. Creasman WT, Morrow CP, Bundry BN, et al. Surgical pathologic spread patterns of endometrial cancer: a Gynecologic Oncology Group Study. Cancer. 1987;60:2035-2041.

8. Gal D, Recio FO, Zamurovic D. The new International Federation of Gynecology and Obstetrics surgical staging and survival rates in early endometrial carcinoma. Cancer. 1992;69:200-202.

9. Kosary CL. FIGO stage, histology, histologic grade, age and race as prognostic factors in determining survival for cancers of the female gynecological system: an analysis of 1973-87 SEER cases of cancers of the endometrium, cervix, ovary, vulva, and vagina. Semin Surg Oncol. 1994;10:31-46.

10. Creasman WT, Kohler MF, Odicino F, et al. Prognosis of papillary serous, clear cell, and grade 3 stage I carcinoma of the endometrium. Gynecol Oncol. 2004;95:593-596.

11. Tsujikawa T, Yoshida Y, Mori T, et al. Uterine tumors: pathophysiologic imaging with $16 \alpha-\left[{ }^{18} \mathrm{~F}\right]$ fluoro- $17 \beta$-estradiol and ${ }^{18} \mathrm{~F}$ fluorodeoxyglucose PET-initial experience. Radiology. 2008;248:599-605.

12. Kiesewetter DO, Kilbourn MR, Landvatter SW, et al. Preparation of four fluorine-18-labeled estrogen and their selective uptake in target tissue of immature rats. J Nucl Med. 1984;25:1212-1221.

13. Mori T, Kasamatsu S, Mosdzianowski C, et al. Automatic synthesis of $16 \alpha-$ $\left[{ }^{18} \mathrm{~F}\right]$ fluoro-17ß-estradiol using a cassette-type $\left[{ }^{18} \mathrm{~F}\right]$ fluorodeoxyglucose synthesizer. Nucl Med Biol. 2006;33:281-286.
14. Belhocine T, De Barsy C, Hustinx R, et al. Usefulness of ${ }^{18} \mathrm{~F}$-FDG PET in the post-therapy surveillance of endometrial carcinoma. Eur J Nucl Med Mol Imaging. 2002;29:1132-1139.

15. Saga T, Higashi T, Ishimori T, et al. Clinical value of FDG-PET in the follow up of post-operative patients with endometrial cancer. Ann Nucl Med. 2003;17:197203.

16. Horowitz NS, Dehdashti F, Herzog TJ, et al. Prospective evaluation of FDG-PET for detecting pelvic and para-aortic lymph node metastasis in uterine corpus cancer. Gynecol Oncol. 2004;95:546-551.

17. Chao A, Chang TC, $\mathrm{Ng} \mathrm{KK}$, et al. ${ }^{18} \mathrm{~F}-\mathrm{FDG}$ PET in the management of endometrial cancer. Eur J Nucl Med Mol Imaging. 2006;33:36-44.

18. Grasel RP, Outwater EK, Siegelman ES, et al. Endometrial polyps: MR imaging features and distinction from endometrial carcinoma. Radiology. 2000;214:4752.

19. Takeuchi M, Matsuzaki K, Uehara H, et al. Pathologies of the uterine endometrial cavity: usual and unusual manifestations and pitfalls on magnetic resonance imaging. Eur Radiol. 2005;15:2244-2255.

20. Mariani A, Webb MJ, Keeney GL, et al. Low-risk corpus cancer: is lymphadenectomy or radiotherapy necessary? Am J Obstet Gynecol. 2000;182: 1506-1519.

21. Hidaka t, Kato K, Yonezawa R, et al. Omission of lymphadenectomy is possible for low-risk corpus cancer. Eur J Surg Oncol. 2007;33: 86-90. 